\title{
Erratum: Structural and quantum-state phase transitions in van der Waals layered materials
}

Heejun Yang, Sung Wng Kim, Manish Chhowalla and Young Hee Lee

Nature Physics 13, 931-937 (2017); published online 17 July 2017; corrected after print 24 October 2017.

In the version of this Progress Article originally published, the title contained a typographical error and should have read 'Structural and quantum-state phase transitions in van der Waals layered materials'.

\section{Erratum: Structural and quantum-state phase transitions in van der Waals layered materials}

Heejun Yang, Sung Wng Kim, Manish Chhowalla and Young Hee Lee

Nature Physics 13, 931-937 (2017); published online 17 July 2017; corrected after print 10 November 2017.

In the version of this Progress Article originally published, one of the $t_{2 \mathrm{~g}}$ states in Fig. 2a was missing; there should have been three. The original and corrected Fig. 2a panels are shown below.

\section{Original Fig. 2a}

a Trigonal prismatic $(1 \mathrm{H})$
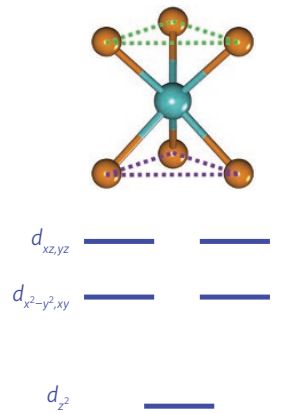

$d_{z^{2}}$
Octahedral (1T)
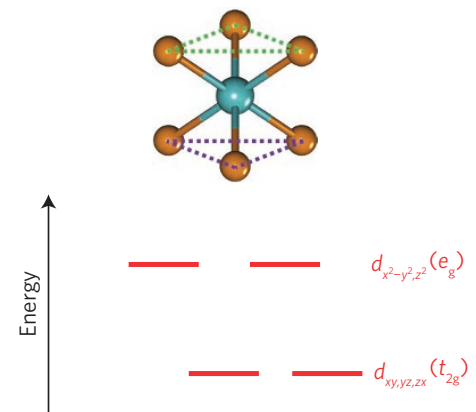

Corrected Fig. 2a

a

Trigonal prismatic $(1 \mathrm{H})$

Octahedral (1T)
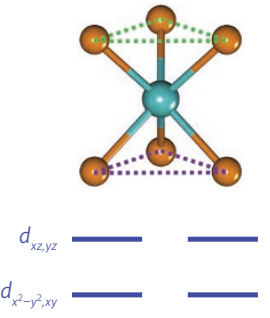

할

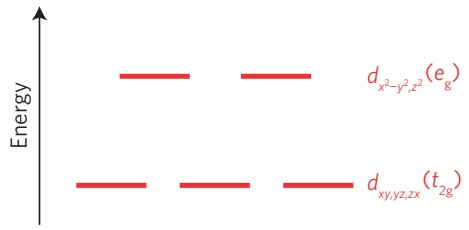

